\title{
Intellectual Property And Academia
}

William A. Dowling (E-mail: William.Dowling@Savstate.edu), Savannah State University V. Blair Dowling (E-mail: Gte378n@prism.gatech.edu), Georgia Tech University

\begin{abstract}
Accompanying the exponential growth in the technology sector in the last decade has been the development and implementation of new policies and protocols regarding intellectual property by many academic institutions. Characteristically, considerable debate has accompanied the process. The purpose of this paper is to explore the relationship between technological progress and the development of university policies and protocols pertaining to intellectual property.

Initially, a set of commonly accepted definitions for "Intellectual Property" (IP) is established. This is accomplished by drawing from federal laws and statutes, the American Association of University Professors guidelines for IP policy content and wording, and several current university policies. As these definitions are developed, it becomes apparent that one must next broach the issue of where software and other new forms of technology-related materials fit into current classifications. This paper includes an overview of current approaches to IP agreements among research-level universities in the United States, and a brief coverage of historical precedents. Special attention is given to recent changes in policies which seem to have been caused by technological advances, and several outside opinions and recommendations for modifications due to technology are presented. The question of whether or not any changes in IP policy are warranted becomes central, and some care is taken to analyze the consequences of various proposals for modification (or lack thereof), concluding with some recommendations on the topic.
\end{abstract}

\section{Background}

1 nitially, the issue of developing a working definition of intellectual property must be resolved. The AAUP suggests that when considering university IP policies, only two types of works need be considered - those that are either copyrightable or patentable (AAUP Special Committee). Federal copyright and patent laws define these categories more explicitly. Copyright protection is given to "original works of authorship fixed in any tangible medium of expression, now known or later developed," (United States Code, Title 17, Chapter 1) and "works of authorship"i. This provides the first of AAUP's two broad categories of intellectual property.

Patents are also covered in the law, specifically, "Whoever invents or discovers any new and useful process, machine, manufacture, or composition of matter, or any new and useful improvement thereof, may obtain a patent therefore, subject to the conditions and requirements of this title." (United States Code, Title 35, Chapter 10). In other words, patents apply to ideas, processes, or machines that "do something," and this is the second sort of IP mentioned by the AAUP.

Most ${ }^{\mathrm{ii}}$ university policies seem to generally follow the convention of defining intellectual property to be encompassed by these categories, though many of them also make specific mention of other items, which they apparently feel don't quite fall under the twin umbrellas of "copyrightable works" and "patentable items". For example, Georgia Institute of Technology (GIT), the University of Georgia (UGA), and Carnegie Mellon University (CMU) all specifically state that IP includes "trade secrets". Additionally, the GIT, UGA, Massachusetts Institute of Technology (MIT), and University of North Carolina at Chapel Hill (UNC) policies also include "trademarks." Of

Readers with comments or questions are encouraged to contact the authors via email.

particular interest is that UGA, GIT, Duke ${ }^{\text {iii }}$ UNC, and MIT all make a note of "software" as one of these additional 
IP components.

The question naturally arises as to why "software" is specifically mentioned by these universities. At first glance, it might seem that most computer programs would fall under either patentable processes (in the case that they accomplished some goal in a new or innovative way), or copyrightable works (for example, software that serves as a medium of artistic expression), and could simply be treated accordingly. However, separating programs into two disjoint categories (copyrightable vs. patentable) is seemingly a subjective task and as such, it seems to create more difficulties than it solves. The AAUP acknowledges this apparent classification difficulty with the statement, "Computer programs fall into a grey area between the two types of intellectual property" (AAUP Special Committee).

Some universities have chosen to deal with this issue by creating a separate (new) section of IP policy specifically for software technology. For example, the University System of Georgia's Board of Regents makes the following statement encouraging new policy on software to be developed:

The University System recognizes the need for enhanced development and dissemination of software technology as a means of expressing both old and new knowledge. Inasmuch as the Board is aware of the dynamic nature of software and that the value of intellectual property comes from the ability of its owner to control its use and that such value is directly related to the degree of protection it enjoys under the law, the Board encourages institutions of the University System to protect such expressions of knowledge by the utilization of appropriate intellectual property laws and the creation of comprehensive software technology transfer policies and procedures (USG Board of Regents, Section 603.01).

Other institutes have appointed a task force to investigate the issues and make suggestions for revision to the current policy. UNC created such a committee (the Intellectual Property Task Force, or IPTF), and the introduction to their final report provides a good summarization of the current feelings on the issue ${ }^{\text {iv }}$. In fact, most universities seem to be in the process of (or have recently completed) revising their intellectual property policies to cope with changing technology ${ }^{\mathrm{v}}$, and the employees of such institutions are expressing serious concern over the nature of these new IP agreements.

Historically, "It has been the prevailing academic practice to treat the faculty member as the copyright owner of works that are created independently and at the faculty member's own initiative for traditional academic purposes," (AAUP) and many current university IP policies uphold this viewpoint. For example, CMU states that their policy (dated 1985) is "based upon the following principles," which include, "there exists a historical tradition of allowing authors to retain ownership of intellectual property rights from textbooks and works of art" (CMU IP Policy). Similarly, and more recently, the Intellectual Property Task Force at UNC developed a suggested new university IP policy in June of 2000, and included in their report, "The policy that evolved is based on a number of important principles: a. The long-established academic tradition wherein ownership of 'traditional scholarly works' (e.g., textbooks, chapters, manuscripts, artistic works) by faculty rests with the author should continue" (UNC Policy). Along with this underlying principle, there have also always been mechanisms in place for profit-sharing schemes when "significant university resources" were used in the development of the intellectual capital. However, "significant usage" is somewhat ambiguous, and universities have generally chosen not to legally pursue cases where these clauses might have been employed, often because of the low profitability of such actions and the potentially shaky legal footing of such agreements to begin with. Not surprisingly, faculty members remain supportive of the precedent that they should be the owners of the copyrights for their works and able to claim all revenue from them. Due to this natural self-interest, university employees therefore do not want to see this policy change.

More recently, and especially in public institutions, there has been a trend to move away from the faculty ownership ideal, in favor of supporting the college's "dedication to teaching, research, and the extension of knowledge to the public" (GIT Faculty Handbook, Section 5.14.01). These universities' current policies more often vest ownership of copyrights and patents with the university itself in order to guarantee the dissemination of the new knowledge to the greater public, as can be seen in the Georgia Tech Research Committee statement "Ownership of Intellectual Property Rights will normally be retained by GTRC. GTRC's logic is to ensure that all licensable know- 
ledge created or invented will be available for public consumption" (GIT Faculty Handbook, Section 5.14.7.9, paragraph 2). The actual rules on when the university gets ownership vary. For example, the UGA Intellectual Property policy gives the ownership of intellectual property developed by university personnel to the originator only under three limited conditions, and sets the burden of proof that these apply on the creator (UGA IP Policy, Section II.D). Georgia Tech takes the concept of significant resource use even farther, granting individuals ownership under the condition that "there is no use, except in a purely incidental way, of GIT resources in the creation of such Intellectual Property (unless such resources are available without charge to the public)" (GIT Faculty Handbook, Section 5.14.6.D). This might seem to be reasonable; the university does need to take steps to make sure it lives up to its mission statements, but one's view might change after reading Robert Gorman's rationale for such policy changes:

The advent of the computer program has, however, changed universities' attitudes and dissipated much of their timidity [toward pressing their rights for ownership in faculty works created using university resources], for two important reasons. First, many computer programs, unlike academic books and articles, are potentially quite remunerative; and second, the programs look much like "inventions" that are at least as much at home under the rubric of patents (where revenue sharing is routine) as under that of copyright" (Gorman).

In other words, he claims that universities do not want to miss out on an opportunity to make a lot of money, and some sort of ownership of the software being developed (or the intellectual property associated with it) is their method of guaranteeing a share in the profits.

Thus, it seems that there are two basic models for the intellectual property policy of the twenty-first century. The first is a direct translation of prior documents into modern language, with allowances for new technologybased IP being only in the definitions of intellectual property. The second approach is to create new doctrines governing software and computer programs, while retaining traditional wording and policy for those categories of intellectual property which were already in existence. Neither of these seems to be a "silver bullet," but rather a patchwork attempt to address the broader issue - whether or not the traditional approach to ownership of intellectual capital by originators in preference to employers (institutions) is still a valid one. The universities have what appears to be a valid claim in profits made from intellectual property developed under their auspices, using their resources, and have an obligation to make new knowledge developed by their constituents available to the public. The faculty are similarly justified in wanting ownership of the patents and copyrights for their work, so that they retain control over publication, modification, and translation. Another not insignificant reason for faculty ownership is the potenetial monetary reward for their efforts (through profits from publications and royalties on inventions). As is the case with most extremes, neither seems to be the optimal solution.

\section{Proposed Model}

Given the preceeding discussion of the general debate over ownership of faculty-developed intellectual capital what will be proposed here is perhaps best understood through an analogy to Wal-Mart's Profit Sharing program for its Associates. Sam Walton, the founder of Wal-Mart, devised a plan to allow the employees of the company to invest in it. Introduced in 1971, the profit sharing and stock ownership plans provide an incentive for employees to work hard as they have shared interest in the overall well-being of the company. Theoretically, their own incomes will be linked to their productivity. University intellectual property policies might do well to adopt the same philosophy. The institutions cannot further increase public knowledge without the cooperation of their faculty members, nor can they continue to operate without some share of the income from the new technologies developed using their resources. The faculty members depend on the support of the scholastic community provided by their employing institution to aid in their research and creation processes, but will have no incentive to continue such work if they receive no benefit from it. However, what we should consider is reversing the roles of the faculty and the university in the analogy to Wal-Mart. Instead of the creator being entitled to some portion of the overall profits from everything created within their parent institution, which makes little sense, the university should take the role of the Associate, and the faculty each as their own Wal-Mart chain. This solution would also address the issue of software and other technology-related intellectual property, by means of a comprehensive agreement signed upon employment, which lays out the following items: 
- What intellectual property works are covered under the "work-for-hire" doctrine ${ }^{\text {vi }}$, and would thus have copyright or patent license vested in the university?

- All ownership of copyrights for material created during the duration of employment would be vested in the creator.

- $\quad$ Ownership of patent rights would be specified as in current agreements.

- $\quad$ A profit-sharing plan on copyrightable materials, perhaps with a sliding scale based on amount of university resources used in development, would be implemented.

- $\quad$ Software would be treated no differently from any other sort of intellectual property, and would be allowed to be classified as copyrightable work or patentable material, depending on how it was filed under U.S. law.

Why does all this matter? The issue of intellectual property rights and ownership of intellectual capital for university faculty may well seem insignificant when put up against many other current societal dilemmas. However, the consequences of the new policies that are being put into place today extend much farther than may be apparent. Clearly, universities face a dilemma. If they pursue their current path and create new and different intellectual property for software, is safe to say two things. One is that there will be legal battles on every front, and the second is that this dilemma will be revisited when technology develops farther and new forms of intellectual capital are created. If universities choose to modify current policy in such a way as to fit computer programs into the patent and copyright categorizations, the underlying debate over who should own faculty-developed IP will continue to simmer, waiting for the next spurt of growth in technology and/or new developments in intellectual capital, to resurface.

\section{Concluding Remarks}

It is clear that a more comprehensive revamping of university policy is essential, but if done incorrectly there will clearly be negative consequences for all parties. If universities choose to put their own interests first, writing policies that afford them more ownership rights and a large percentage of the profits from professorial work, then self-interest will dictate that the brightest and most creative minds will no longer be attracted to positions at universities. The most immediate cost will be that the next generation will not benefit from their knowledge and expertise. Eventually, mediocrity may well become the norm among university faculty, and the United States will continue to fall farther behind in the world's intellectual and educational community.

On the flip side, if the AAUP and other professional groups for college educators get their way, there will be no disincentive for bright and creative individuals to associate themselves with universities. However, the institutions themselves will have significantly fewer resources to offer. Public universities are unlikely to receive increases in state subsidies in order to provide resources for faculty research where there are no compensating benefits. If universities are unable to claim any of the returns on their investments in faculty creations, they are far less likely to expend precious operating funds to support such projects.

Both outcomes discussed above are fraught with undesirables. There is however an alternative, a middle ground solution offered here for consideration wherein, we believe, benefits accrue to all parties.

\section{Works Cited $^{\text {vii }}$}

1. American Association of University Professors Special Committee on Distance Learning and Intellectual Property Issues. "Suggestions and Guidelines Sample Language for Institutional Policies and Contract Language." 21 June 2002. <http://www.aaup.org/ldup/ipguide.htm>

2. American Association of University Professors Statement on Copyright. 15 July 2002. <http://www.aaup.org/lduc/stcopyrt.htm>

3. Carnegie Mellon University. Intellectual Property Policy of Carnegie Mellon University.15 July 2002. <http://www.cmu.edu/policies/documents/IntellProp.html>

4. Georgia Institute of Technology. Georgia Tech Faculty Handbook. 21 June 2002. http://www.academic.gatech.edu/handbook/Section 6/Intellectual.html

5. Gorman, Robert A. "Intellectual Property: The Rights of Faculty as Creators and Users." Academe, 
<http://www.aaup.org/events/archived/speeches,\%20articles/GORMNart.htm> May/June, 1998. 21 June 2002.

6. "Proposed Revisions to the Georgia Tech Faculty Handbook Related to Commercialization and Intellectual Property Policy." 21 June 2002. <http://www.facultysenate.gatech.edu/zzzrevIPpolicy>

7. The University System of Georgia. Board of Regents Policy Manual. 21 June 2002. <http://www.usg.edu/admin/policy>

8. United States Code, Title 17, Chapter 1.15 July 2002. <http://www.copyright.gov/title17/92chap1.html>

9. United States Code, Title 35, Chapter 10. <http://uscode.house.gov/DOWNLOAD/35C10.DOC>15 July 2002.

10. University of Georgia. Intellectual Property Policy of the University of Georgia. 21 June 2002. <http://www.ovpr.uga.edu/rpph/rph_chp2.html\#intellectual\%20property>

11. University of North Carolina at Chapel Hill. Copyright and Patent Policies. <http://www.northcarolina.edu/docs/aa/research/copyright/PatentAndCopyrightPolicies.pdf>

\footnotetext{
${ }^{\text {i }}$ Excerpts from Title 17, Chapter 1 of the United States Code Appendix A: Excerpts from Title 17, Chapter 1 of the United States Code (Taken from http://www.copyright.gov/title17/92chap1.html)
}

\section{Section 102. Subject matter of copyright: In general}

(a) Copyright protection subsists, in accordance with this title, in original works of authorship fixed in any tangible medium of expression, now known or later developed, from which they can be perceived, reproduced, or otherwise communicated, either directly or with the aid of a machine or device. Works of authorship include the following categories:

1) literary works;

2) musical works, including any accompanying words;

3) dramatic works, including any accompanying music;

4) pantomimes and choreographic works;

5) pictorial, graphic, and sculptural works;

6) motion pictures and other audiovisual works;

7) sound recordings; and

8) architectural works.

(b) In no case does copyright protection for an original work of authorship extend to any idea, procedure, process, system, method of operation, concept, principle, or discovery, regardless of the form in which it is described, explained, illustrated, or embodied in such work.

\section{from Section 101: Definitions}

"Literary works" are works, other than audiovisual works, expressed in words, numbers, or other verbal or numerical symbols or indicia, regardless of the nature of the material objects, such as books, periodicals, manuscripts, phonorecords, film, tapes, disks, or cards, in which they are embodied.

${ }^{\text {ii }}$ Carnegie Mellon University: http://www.cmu.edu/policies/documents/IntellProp.html Duke: http://www.duke.edu/web/ost/invention/docs/IntelProp.pdf and http://www.duke.edu/web/ost/policies/ppatent.htm

Georgia Institute of Technology:

http://www.academic.gatech.edu/handbook/Section6/Intellectual.html

Massachusetts Institute of Technology: 
http://web.mit.edu/policies/13.1.html

University of Georgia at Athens:

http://www.ovpr.uga.edu/rpph/rph_chp2.html\#INTELLECTUAL\%20PROPERTY

University of North Carolina at Chapel Hill:

http://www.northcarolina.edu/docs/aa/research/copyright/PatentAndCopyrightPolicies.pdf.

iii Duke makes special reference to "computer programs, when the programs are primarily created to perform utilitarian tasks" in section II.A.1 of its policy.

${ }^{\text {iv }}$ Excerpts from the Intellectual Property Task Force Report, University of North Carolina, June 2000

(http://://www.northcarolina.edu/docs/aa/research/copyright/IPTF.pdf) (from Introduction, paragraph 1)

Intellectual property issues increasingly dominate discussions on University of North Carolina campuses. Many of the issues have been around for years, but other concerns have gained prominence only with the advent of the digital environment.

(from Introduction, paragraph 3)

On the ownership side, faculty, staff and students are creating a wider range of copyrighted works than ever before. Although the long tradition in American higher education recognizes faculty ownership of works they create, the complexities of ownership and the rights of use created by digital communication make it essential to reexamine this issue. The advent of distance learning and online courses created by faculty, either at the request of the University, or at least with its blessing, raises the issue of whether the University should own or control these courses or, at a minimum, retain a nonexclusive license to use the courses. Both faculty and the University have much at stake. For faculty, one of the rewards of serving as a faculty member is the ability to own the copyright in works they create and to benefit from any publication of them. Today, however, the University is committing more and more resources to the creation of these works, and thus its investment is greater than ever before. Because of the changing environment for the creation and commercialization of copyrighted works,

${ }^{\mathrm{v}}$ For example, among the university policies examined for this paper (see $i i$ above), there have been proposed or implemented revisions to the policies at GIT, UNC, UGA, and Duke within the last 8 years.

${ }^{\text {vi }}$ Excerpts from Title 17, Chapter 1 of the United States Code Appendix A: Excerpts from Title 17, Chapter 1 of the United States Code (Taken from http://www.copyright.gov/title17/92chap1.html) from Section 101: Definitions

A "work made for hire" is-

1) a work prepared by an employee within the scope of his or her employment; or

2) a work specially ordered or commissioned for use as a contribution to a collective work, as a part of a motion picture or other audiovisual work, as a translation, as a supplementary work, as a compilation, as an instructional text, as a test, as answer material for a test, or as an atlas, if the parties expressly agree in a written instrument signed by them that the work shall be considered a work made for hire. For the purpose of the foregoing sentence, a "supplementary work" is a work prepared for publication as a secondary adjunct to a work by another author for the purpose of introducing, concluding, illustrating, explaining, revising, commenting upon, or assisting in the use of the other work, such as forewords, afterwords, pictorial illustrations, maps, charts, tables, editorial notes, musical arrangements, answer material for tests, bibliographies, appendixes, and indexes, and an "instructional text" is a literary, pictorial, or graphic work prepared for publication and with the purpose of use in systematic instructional activities.

In determining whether any work is eligible to be considered a work made for hire under paragraph (2), neither the amendment contained in section 1011(d) of the Intellectual Property and Communications Omnibus Reform 
Act of 1999, as enacted by section 1000(a)(9) of Public Law 106-113, nor the deletion of the words added by that amendment--

A) shall be considered or otherwise given any legal significance, or

B) shall be interpreted to indicate congressional approval or disapproval of, or acquiescence in, any judicial determination,

by the courts or the Copyright Office. Paragraph (2) shall be interpreted as if both section 2(a)(1) of the Work Made For Hire and Copyright Corrections Act of 2000 and section 1011(d) of the Intellectual Property and Communications Omnibus Reform Act of 1999, as enacted by section 1000(a)(9) of Public Law 106-113, were never enacted, and without regard to any inaction or awareness by the Congress at any time of any judicial determinations.

${ }^{\text {vii }}$ University Intellectual Property Policies aren't listed on this page unless they were directly quoted in the text of the paper. However, ideas were drawn from all the policies listed in ii above.

Notes

Notes 